\title{
Luteolin Promotes Cell Apoptosis by Inducing Autophagy in Hepatocellular Carcinoma
}

\author{
Zhijia Cao ${ }^{\mathrm{a}}$ Huainian Zhang ${ }^{\mathrm{a}}$ Xiaoyan Caia,b Wei Fang ${ }^{\mathrm{a}}$ Dong Chai ${ }^{\mathrm{a}}$ Ying Wen ${ }^{\mathrm{a}}$ \\ Hongsheng Chen ${ }^{\mathrm{a}}$ Fujiang Chu ${ }^{\mathrm{c}}$ Yongli Zhang ${ }^{\mathrm{a}}$ \\ aDepartment of Biology, School of Basic Courses, Guangdong Pharmaceutical University, Guangzhou, \\ bHubei University of Medicine, Shiyan, 'Guangdong Provincial Key Laboratory of Pharmaceutical \\ Bioactive Substances, Guangdong Pharmaceutical University, Guangzhou, People's Republic of China
}

\author{
Key Words \\ Luteolin • Apoptosis • Autophagy • SMMC-7721 cells
}

\begin{abstract}
Background/Aims: Hepatocellular carcinoma (HCC) is the most common primary liver malignancy and is a leading cause of cancer-related death worldwide. Luteolin, a flavonoid from traditional Chinese medicine, shows anti-cancer activity in many cancer cells, including HCC. However, the mechanism underlying the action of luteolin in HCC, especially its role in regulating cell autophagy, remains unclear. In the present study, we investigated the role of luteolin in regulating cell autophagy and the role of autophagy in luteolin-induced apoptosis. Methods: The 3-(4,5-dimethythiazol-2-yl)-2,5-diphenyl tetrazolium bromide assay (MTT) was used to investigate cell viability. Flow cytometry analysis was used to detect the cell cycle and cell apoptosis. Hoechst 33342 staining was used to detect cell apoptosis. Transmission electron microscopy was used to investigate autophagy. qRT-PCR and western blotting were used to detect apoptosis- and autophagy-related mRNAs and proteins. Results: Luteolin reduced the viability of SMMC-7721 cells in a time and dose-dependent manner, and induced significant G0/G1-phase arrest. In addition, the results of flow cytometry analysis and Hoechst 33342 staining showed that luteolin treatment increased the number of apoptotic cells obviously, and the results of qRT-PCR and western blotting showed that luteolin treatment increased caspase 8 and decreased bcl-2 at the mRNA and protein levels. Furthermore, luteolin increased the number of intracellular autophagosomes, promoted LC3B-I conversion to LC3B-II, and increased Beclin 1 expression. Finally, co-treatment with the autophagy inhibitor chloroquine weakened the effects of luteolin on cell apoptosis. Conclusion: Luteolin induced apoptosis in human liver cancer SMMC-7721 cells, partially via autophagy. Thus, luteolin could be used as a regulator of autophagy in HCC treatment.




\section{Cellular Physiology Cell Physiol Biochem 2017;43:1803-1812 \begin{tabular}{ll|l} 
and Biochemistry & $\begin{array}{l}\text { DOI: 10.1159/000484066 } \\
\text { Published online: October 19, } 2017\end{array}$ & $\begin{array}{l}\text { O 2017 The Author(s). Published by S. Karger AG, Basel } \\
\text { www.karger.com/cpb }\end{array}$ \\
\cline { 2 - 3 }
\end{tabular} \\ Cao et al.: Luteolin is a Regulator of Autophagy in HCC}

\section{Introduction}

Hepatocellular carcinoma (HCC) is the most common primary liver malignancy and is a leading cause of cancer-related death worldwide. In China in 2011, HCC was the fourth most common cancer and the second most common cause of death [1]. Surgery, liver transplantation, radiofrequency ablation, and chemotherapy can be used to treat HCC [2]. However, only a few early stage liver cancers can be diagnosed and treated successfully. For advanced stage HCC, there are still no suitable drugs or therapies [2]. Most treatments used for HCC are non-selective, cytotoxic molecules that have significant side effects. Therefore, it is important to find safe and effective new agents to treat HCC.

Luteolin (3',4',5, 7-tetrahydroxyflavone) is an abundant flavonoid that is present in many types of plants, including vegetables, fruits, and medicinal herbs. Plants rich in luteolin have been used in Chinese traditional medicine to treat various diseases, such as hypertension, inflammatory disorders, and cancer $[3,4]$. The anti-cancer activities of luteolin have been demonstrated in many cancer cells, such as pancreatic cancer, prostate cancer, breast cancer, colorectal cancer, and ovarian cancer [5-8]. In addition, luteolin could upregulate the mRNA expression level of intercellular adhesion molecule-1, a tumor suppressor gene [9], in mouse H22 hepatoma cells [10]. Luteolin synergizes the antitumor effects of 5 -fluorouracil against human HCC cells [11]. In addition, luteolin plays a growth inhibition role in the HCC cell line HepG2 [12]. These results in HCC cells indicated that luteolin had anti-cancer activity. However, luteolin's regulatory mechanism in HCC, especially its role in regulating cell autophagy, remains unclear.

Autophagy is a catabolic process by which cytoplasmic components, such as damaged organelles, aged proteins, and damaged proteins, are sequestered by a double-membrane autophagosome, and delivered to the lysosome for degradation [13]. Basal levels of autophagy are required for cellular homeostasis. Autophagy is upregulated under various cellular stresses, such as infection, starvation, organelle damage, and protein aggregation $[13,14]$. Autophagy has complicated functions in different stages of cancer [15]. On the one hand, autophagy prevents tumor initiation, acting as a suppressor pathway. On the other hand, autophagy contributes to tumor growth and progression by attenuating cellular metabolic stress, acting as a survival pathway [15]. Autophagy is regarded as a potential target for anticancer therapy $[15,16]$. One of our aims was to determine whether luteolin acts as a regulator of autophagy in HCC.

Apoptosis, first described by Kerr et al., is thought to be the principal anti-cancer mechanism, and has been studied widely as a major mechanism of mediated cell death $[17,18]$. However, the interplay between apoptosis and autophagy is complex and remains unclear. In this study, we investigated the effects of luteolin on cell proliferation, apoptosis, and autophagy in human hepatocellular carcinoma SMMC-7721 cells. We also studied the relationship between apoptosis and autophagy. Our results indicated that luteolin promotes cell apoptosis by inducing autophagy; thus, luteolin might be useful as a regulator of autophagy in HCC.

\section{Materials and Methods}

Cell culture and cell treatment

The human HCC cell line SMMC-7721 was purchased from the Institute of Cell Bank/Institutes for Biological Sciences (Shanghai, China). Cells were cultured in Dulbecco's modified Eagle's medium (DMEM, Hyclone, Logan, UT, USA) supplemented with 10\% fetal bovine serum (FBS, Sijiqing, Hangzhou, China), $100 \mathrm{U} / \mathrm{mL}$ penicillin, and $100 \mu \mathrm{g} / \mathrm{mL}$ streptomycin at $37{ }^{\circ} \mathrm{C}$ in a humidified atmosphere containing $5 \%$ $\mathrm{CO}_{2}$. Luteolin was purchased from the National Institute for the Control of Pharmaceutical and Biological Products (Beijing, China), and was dissolved in dimethyl sulfoxide (DMSO, Sigma-Aldrich, St. Louis, MO, USA) to stock concentrations of $100 \mathrm{mM}$ at $-20^{\circ} \mathrm{C}$. 


\section{Cellular Physiology Cell Physiol Biochem 2017;43:1803-1812 \begin{tabular}{l|l|l} 
and Biochemistry Published onlıne: October 19, 2017 & $\begin{array}{l}\text { (c) } 2017 \text { The Author(s). Published by S. Karger AG, Basel } \\
\text { www.karger.com/cpb }\end{array}$ \\
\hline
\end{tabular}}

Cao et al.: Luteolin is a Regulator of Autophagy in HCC

\section{Cell viability assay}

SMMC-7721 cells were seeded into 96-well culture plates at a density of $1.5 \times 10^{4}$ cells/well in 100 $\mu \mathrm{L}$ of medium and treated with different concentrations of luteolin $(0,12.5,25,50,100$, and $200 \mu \mathrm{M})$ for 24, 48, and $72 \mathrm{~h}$. Cell viability assays were carried out using a 3-(4, 5-dimethythiazol-2-yl)-2, 5-diphenyl tetrazolium bromide (MTT) Cell Proliferation and Cytotoxicity Assay Kit, according to the manufacturer's instructions (Beyotime, Shanghai, China). At each time point, the MTT labeling reagent $(5 \mathrm{mg} / \mathrm{mL}, 15 \mu \mathrm{L} /$ well) was added, and the cells were cultured for an additional $4 \mathrm{~h}$ at $37^{\circ} \mathrm{C}$. The medium was aspirated, and formazan dissolved in DMSO was added (200 $\mu \mathrm{L} /$ well). The optical density (OD) of each well was measured at $490 \mathrm{~nm}$ using a microplate reader (multiscan MK3; Thermo Fisher Scientific, Waltham, MA, USA). Cell viability was determined using the following equation:

$$
\text { Cell viability }=\frac{O D \text { of sample }-O D \text { of blank }}{O D \text { of control }-O D \text { of blank }} \times 100
$$

Flow cytometry analysis for the cell cycle and cell apoptosis

The cell cycle and cell apoptosis were analyzed using a Cell Cycle Analysis Kit and an Annexin V-FITC Apoptosis Detection Kit (Beyotime), respectively, according to the manufacturer's instructions. After treatment with 25,50 , and $100 \mu \mathrm{M}$ luteolin for $48 \mathrm{~h}$, SMMC-7721 cells were harvested and washed twice with phosphate buffered saline (PBS). For the cell cycle analysis, each group of cells was fixed with $70 \%$ ethanol overnight at $4{ }^{\circ} \mathrm{C}$. The cells were washed with PBS after centrifugation and resuspended in PBS. Then, $100 \mu \mathrm{L}$ of RNase was added and the cells were incubated for 10 min. Propidium iodide (PI) (400 $\mu \mathrm{L} ; 10 \mu \mathrm{g} / \mathrm{mL}$ ) was then added, and the samples were kept in the dark for $30 \mathrm{~min}$. Immediately, the cells were analyzed using a flow cytometer. For the apoptosis assay analysis, the cells were suspended in $100 \mu \mathrm{L}$ binding buffer and stained with $5 \mu \mathrm{L}$ annexin V-FITC and $5 \mu \mathrm{L}$ PI for $15 \mathrm{~min}$ in the dark at room temperature $\left(19-21^{\circ} \mathrm{C}\right)$. Binding buffer $(400 \mu \mathrm{L})$ was then added. Finally, the cells were detected and quantified using a flow cytometer within $1 \mathrm{~h}$. The data were analyzed using winMDI 2.9.

\section{Hoechst 33342 staining}

Cells were seeded in 24-well culture plates overnight and then treated with 25, 50, and $100 \mu \mathrm{M}$ luteolin for $48 \mathrm{~h}$. After treatment, the attached cells were washed twice with PBS, stained with Hoechst 33342 dye (3 $\mathrm{mM}$ in PBS) for $10 \mathrm{~min}$ at room temperature, washed again, and observed under a fluorescence microscope.

\section{RNA extraction and quantitative reverse transcription PCR ( $q R T-P C R$ )}

Cells were treated with 25, 50, and $100 \mu \mathrm{M}$ luteolin for $48 \mathrm{~h}$, and then the total RNA was extracted using the Trizol reagent (Invitrogen, Carlsbad, CA, USA), according to the recommended protocol. Total RNA was reverse-transcribed to synthesize single strand cDNA using an oligo(dT) primer. Quantitative PCR was performed using the SYBR Premix Ex Taq (Takara, Dalian, China). The actin gene was used as an internal control. The primer sequences used in qRT-PCR are shown in Table 1. Gene expression was measured in triplicate and quantified using the $2^{-\Delta \Delta C T}$ method [19] normalized to the actin control.

\section{Protein extraction and western blotting analysis}

Cells were treated with 25, 50, and $100 \mu \mathrm{M}$ luteolin for $48 \mathrm{~h}$, washed twice with PBS, and re-suspended in radioimmunoprecipitation assay (RIPA) lysis buffer (RIPA: phenylmethylsulfonyl fluoride (PMSF) =100:1) for $30 \mathrm{~min}$, followed by centrifugation for $10 \mathrm{~min}$ at $12,000 \mathrm{rpm}$. The proteins ( $40 \mu \mathrm{g} / \mathrm{well}$ ) were separated by $12 \%$ sodium dodecylsulfate polyacrylamide gel electrophoresis (SDS-PAGE) and transferred to polyvinylidene fluoride membranes. After blocking with 5\% non-fat milk, the membranes were incubated with rabbit anti-LC3B (Bioss, China), rabbit anticaspase8, rabbit anti-bcl-2, rabbit antibeclin1, and mouse anti- $\beta$-actin (Boster) primary antibodies. After incubating for $1 \mathrm{~h}$ with the primary

Table 1. The primers used in this study. All primers were synthesized by Sangon (Shanghai, China)

\begin{tabular}{lcc}
\hline Gene & \multicolumn{1}{c}{ Forward 5' $-3^{\prime}$} & Reverse 5' $^{\prime}$ - $^{\prime}$ \\
\hline Actin & TGACGTGGACATCCGCAAAG & CTGGAAGGTGGACAGCGAGG \\
Bcl-2 & GTTTGATTTCTCCTGGCTGTCTC & GAACCTTTTGCATATTTGTTTGG \\
Caspase-8 & GGAGGAGTTGTGTGGGGTAA & CCTGCATCCAAGTGTGTTCC \\
LC3B & AACCACACCCAAAGTCCTCA & CTGGTACACTGCTGCTTTCA \\
Beclin1 & GACACTCAGCTCAACGTCAC & CTGCCACTATCTTGCGGTTC \\
\hline
\end{tabular}


antibodies, the membranes were washed with Tris buffered saline containing 0.05\% Tween-20 (TBST) and incubated with a secondary antibody. After washing with TBST, the immunoreactive bands were visualized using the ECL Plus reagent from Pierce Thermo Scientific.

\section{Transmission electron microscopy}

Cells were treated with 25, 50, and $100 \mu \mathrm{M}$ luteolin for $48 \mathrm{~h}$. After treatment, the cells were harvested and fixed with $2.5 \%$ glutaraldehyde overnight at $4{ }^{\circ} \mathrm{C}$. After washing with $0.1 \%$ sodium cacodylate buffer, the cells were post-fixed with $1 \%$ osmium tetroxide for $30 \mathrm{~min}$, stained with $2 \%$ uranyl acetate at $4{ }^{\circ} \mathrm{C}$, dehydrated in a graded ethanol series, and embedded in spur resin. Ultra-thin $(70 \mathrm{~nm})$ sections were cut on a Reichert Ultra cut microtome, post-stained with uranyl acetate and lead citrate, and washed with water. The sections were examined by a transmission electron microscope operated at $60 \mathrm{kV}$.

\section{Statistical analysis}

The data were expressed as the mean \pm SD. Statistical analysis was performed using a paired Student t-test. In all of the analyses, $\mathrm{P}<0.05$ was considered statistically significant.

\section{Results}

\section{Effect of luteolin on cell viability in SMMC-7721 cells}

To investigate the effect of luteolin on cell viability, SMMC-7721 cells were treated with different concentrations of luteolin and cell viability was detected by MTT assays. As shown in Fig. $1 \mathrm{~A}$ and $1 \mathrm{~B}$, luteolin could reduce SMMC-7721 viability at concentrations ranging from 12.5 to $200 \mu \mathrm{M}$ at 24,48 , and $72 \mathrm{~h}$. The $\mathrm{IC}_{50}$ values of luteolin on SMMC-7721 cells at 24,48 , and $72 \mathrm{~h}$ were $103.1 \mu \mathrm{M}, 46.89 \mu \mathrm{M}$, and $34.24 \mu \mathrm{M}$, respectively. In addition, the

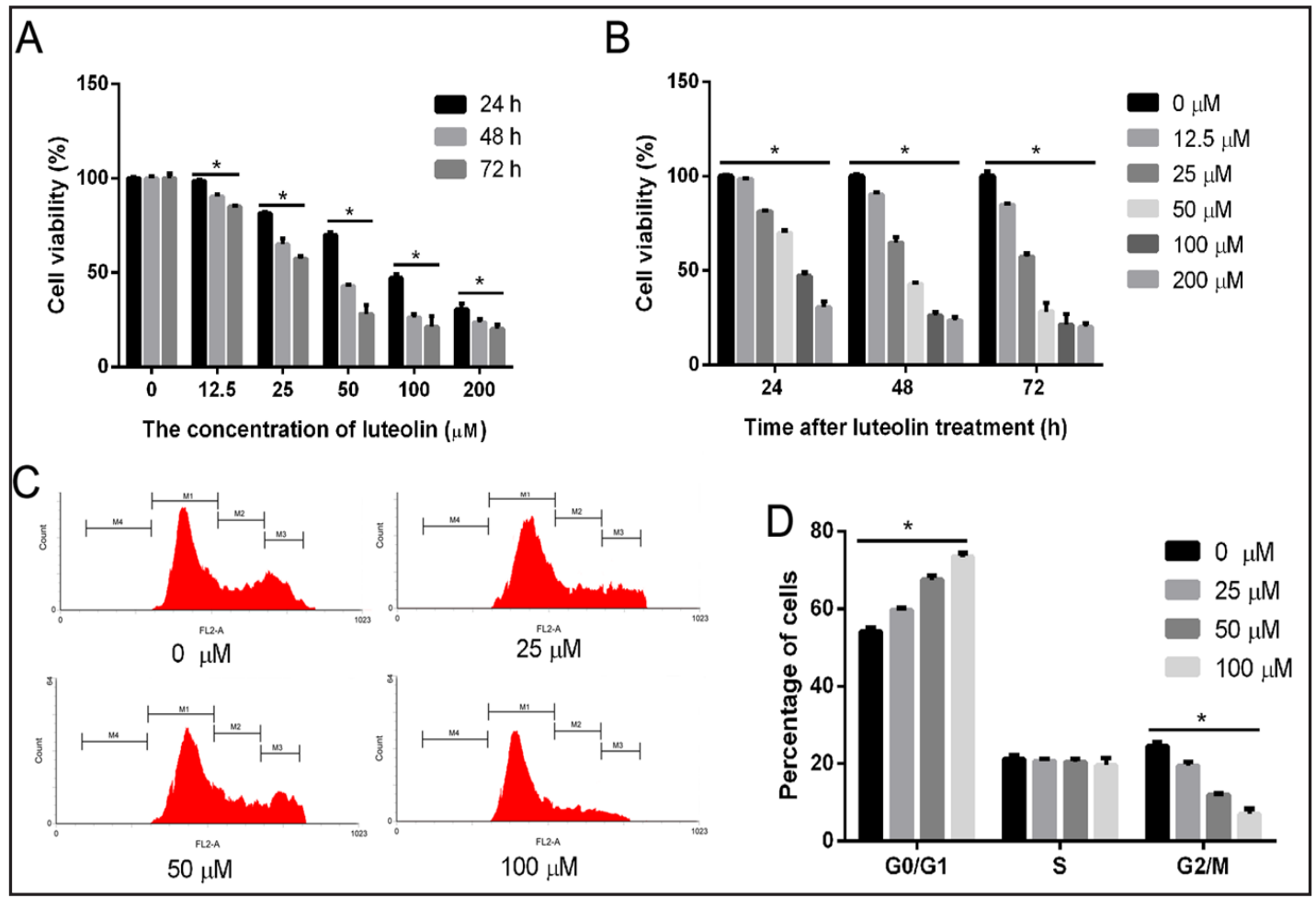

Fig. 1. Effect of luteolin on cell viability and the cell cycle. A-B: SMMC-7721 cells were treated with different concentrations of luteolin $(0,12.5,25,50,100$, and $200 \mu \mathrm{M})$ for 24,48 , and $72 \mathrm{~h}$ and cell viability was detected by MTT assays. C: Representative graphs of the flow cytometry analysis of the cell cycle after 25, 50, and $100 \mu \mathrm{M}$ luteolin for $48 \mathrm{~h}$. M1: G0/G1 stage, M2:S stage, M3: G2/M stage, M4: Apoptotic cell peak. D: The statistical results of flow cytometry analysis of the cell cycle. ${ }^{*} \mathrm{P}<0.05$. 
statistical analysis showed that the effect of luteolin on cell viability of SMMC-7721 cells was time-dependent and dose-dependent (Fig. 1A and 1B). To determine the mechanism by which luteolin reduces cell viability, we used flow cytometry to determine the distribution of SMMC-7721 cells in the cell cycle after treatment with 25,50, and $100 \mu \mathrm{M}$ luteolin for 48 h. As shown in Fig. 1C and 1D, luteolin treatment induced a significant G0/G1-phase arrest, and the percentage of cells in the G2/M-phase decreased significantly.

\section{Effect of luteolin on cell apoptosis in SMMC-7721 cells}

To investigate the effect of luteolin on cell apoptosis, SMMC-7721 cells were treated with 25, 50, or $100 \mu \mathrm{M}$ luteolin for $48 \mathrm{~h}$. Each group was then harvested for flow cytometry analysis, Hoechst 33342 staining, qRT-PCR, and western blotting. The results showed that luteolin treatment increased the percentage of early apoptosis, late apoptosis, and total

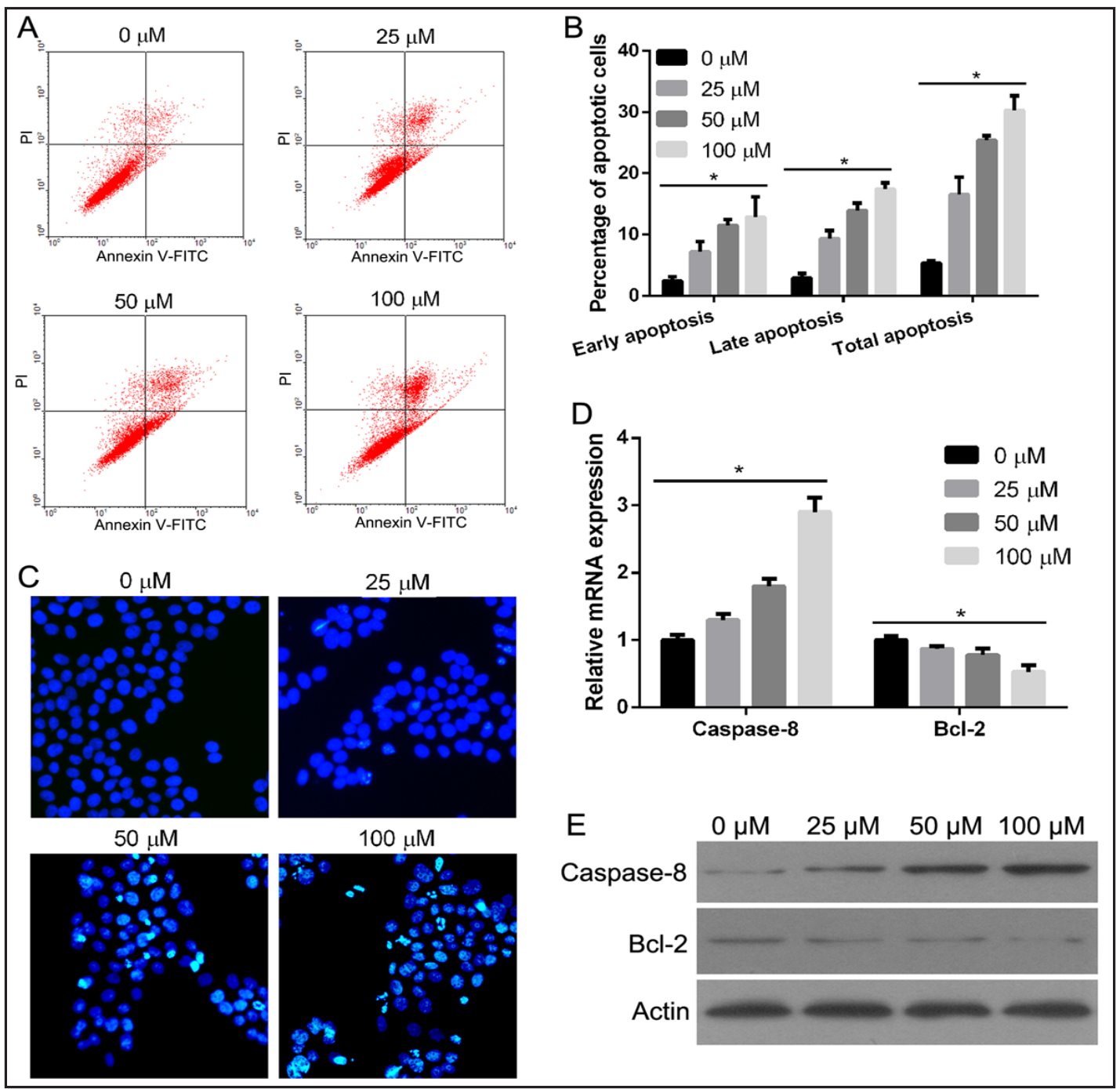

Fig. 2. Effect of luteolin on cell apoptosis. A: Representative graphs of the flow cytometry analysis of cell apoptosis after $0,25,50$, and $100 \mu \mathrm{M}$ luteolin for $48 \mathrm{~h}$. In all four plots, viable cells are seen in the left lower quadrant (FITC- $/ \mathrm{PI}^{-}$); early apoptotic cells in the right lower quadrant (FITC $/ \mathrm{PI}^{-}$); late apoptotic cells in the right upper quadrant $\left(\mathrm{FITC}^{+} / \mathrm{PI}^{+}\right)$; and necrotic cells in the left upper quadrant $\left(\mathrm{FITC}^{-} / \mathrm{PI}^{+}\right)$. B: The statistical results of the flow cytometry analysis of cell apoptosis. C: Representative graphs of Hoechst 33342 staining. D: The mRNA expression levels of caspase-8 and bcl-2 after luteolin treatment. E: The protein expression levels of caspase- 8 and bcl- 2 after luteolin treatment. ${ }^{*} \mathrm{P}<0.05$.

\section{KARGER}


Fig. 3. The effect of luteolin on autophagy of SMMC-7721 cells. SMMC-7721 cells were treated with $0,25,50$, or $100 \mu$ M luteolin for $48 \mathrm{~h}$ and harvested for transmission electron microscopy (A), qRT-PCR (B), and western blotting (C) to detect LC3B and beclin1 expression.

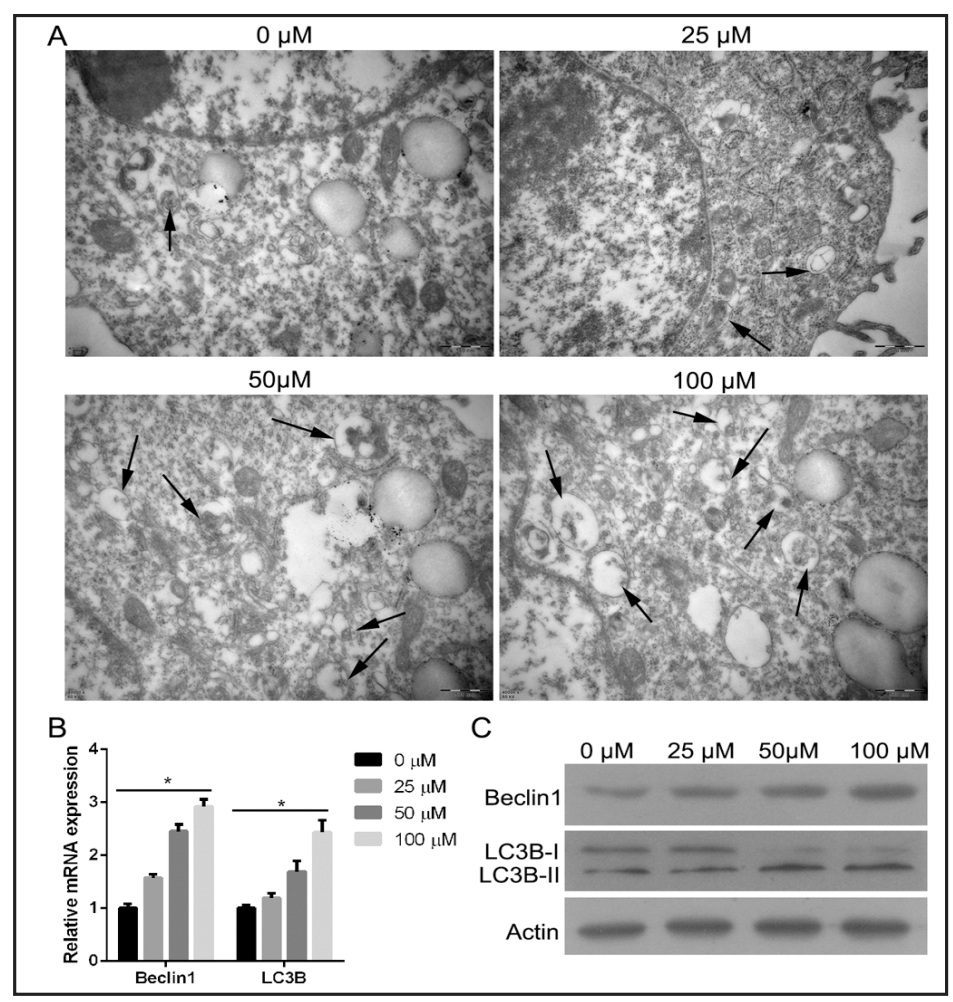

apoptosis in SMMC-7721 cells (Fig. 2A and 2B). In addition, the statistical analysis showed that the effect of luteolin on the apoptosis of SMMC-7721 cells was dose-dependent (Fig. 2B). Hoechst 33342 staining also indicated that luteolin treatment could increase the number of apoptotic cells (Fig. 2C). Furthermore, qRT-PCR and western blotting showed that luteolin treatment increased caspase 8 and decreased bcl-2 at the mRNA and protein levels (Fig. 2D and 2E). The statistical analysis showed that the effect of luteolin on caspase 8 and bcl-2 mRNA levels in SMMC-7721 cells was dose-dependent (Fig. 2D).

\section{Effect of luteolin on cell autophagy in SMMC-7721 cells}

To detect the effect of luteolin on SMMC-7721 cell autophagy, the formation of autophagosomes was observed using transmission electron microscopy. As shown in Fig. $3 \mathrm{~A}$, the number of intracellular autophagosomes after treatment with 25,50 , or $100 \mu \mathrm{M}$ luteolin for $48 \mathrm{~h}$ increased compared with cells treated with $0 \mu \mathrm{M}$ luteolin. In addition, the number of intracellular autophagosomes increased with increasing luteolin concentration. Furthermore, to determine the effect of luteolin treatment on cell autophagy, the mRNA and protein expressions of the autophagy-related genes $L C 3 B$ and BECN1 (beclin1) were examined using qRT-PCR and western blotting, respectively. As shown in Fig. $3 B, L C 3 B$ and $B E C N 1$ mRNA levels increased after treatment with 25,50 , or $100 \mu \mathrm{M}$ luteolin and this increase was dose-dependent. The western blotting results showed that the conversion of LC3B-I to LC3B-II and beclin1 levels were increased by treatment with luteolin compared with cells treated with $0 \mu \mathrm{M}$ luteolin.

The effect of co-treatment with luteolin and the autophagy inhibitor chloroquine on cell apoptosis

To investigate the role of autophagy in luteolin-induced cell apoptosis, the autophagy inhibitor chloroquine was used to block autophagy before luteolin treatment. The results showed that co-treatment with luteolin and chloroquine decreased the percentage of early apoptosis, late apoptosis, and total apoptosis in SMMC-7721 cells (Fig. 4A and 4B) compared with cells treated with $100 \mu \mathrm{M}$ luteolin only. Hoechst 33342 staining also indicated that luteolin and chloroquine co-treatment decreased the number of apoptotic cells (Fig. 4C). 


\section{Cellular Physiology Cell Physiol Biochem 2017;43:1803-1812 \begin{tabular}{ll|l} 
DOI: 10.1159/000484066 & 2017 The Author(s). Published by S. Karger AG, Basel \\
www.karger.com/cpb
\end{tabular} \\ Cao et al.: Luteolin is a Regulator of Autophagy in HCC}

Fig. 4. Effect of luteolin (Lu) and chloroquine (CQ) co-treatment on cell apoptosis. SMMC-7721 cells were treated with $0 \mu \mathrm{M}$ luteolin, $100 \mu \mathrm{M}$ luteolin, and $100 \mu \mathrm{M}$ luteolin plus CQ treatment for $48 \mathrm{~h}$, and the cells were harvested for flow cytometry, Hoechst 33342 staining, qRT-PCR, and western blotting. A: Representative graphs of flow cytometry analysis of cell apoptosis. In all four plots, viable cells are seen in the left lower quadrant (FITC-PI'); early apoptotic cells in the right lower quadrant $\left(\mathrm{FITC}^{+} / \mathrm{PI}^{-}\right)$; late apoptotic cells in the right upper quadrant $\left(\mathrm{FITC}^{+} / \mathrm{PI}^{+}\right)$; and necrotic cells in the left upper quadrant $\left(\right.$ FITC $^{-} / \mathrm{PI}^{+}$). B: The statistical results of flow cytometry analysis of cell apoptosis. C: Representative graphs of Hoechst 33342
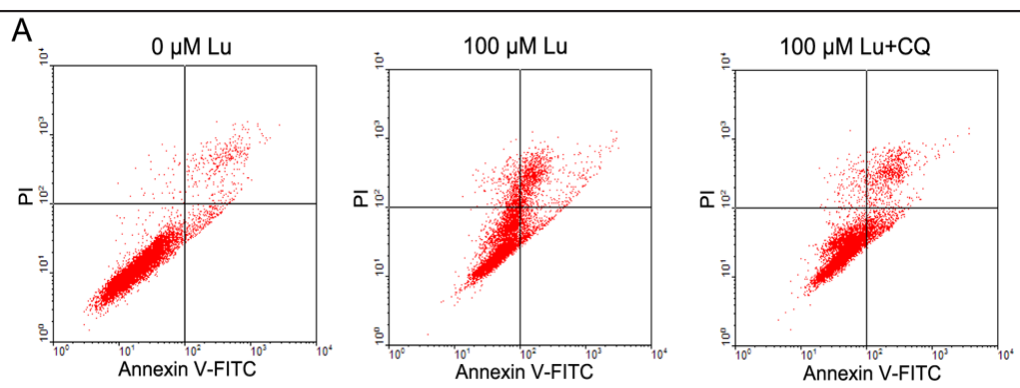

B

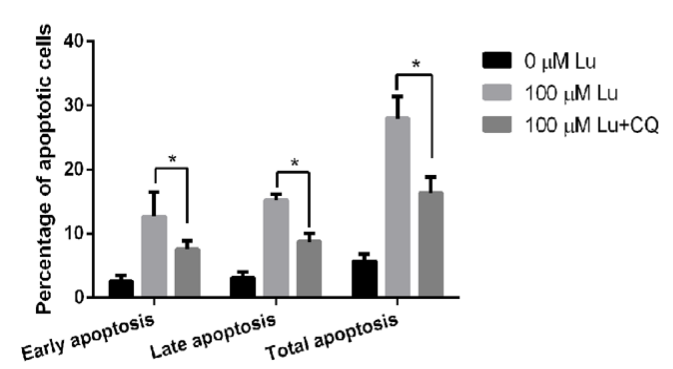

C
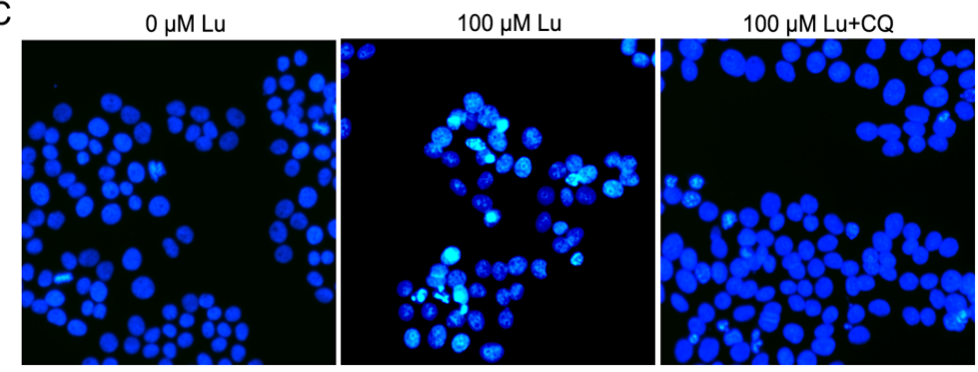

D

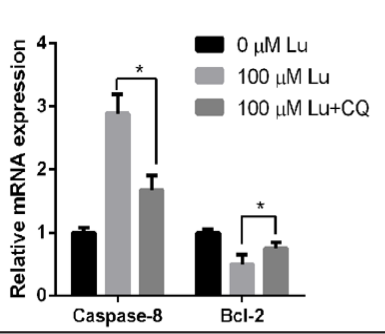

E

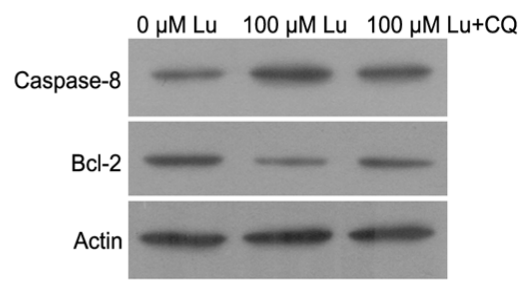

staining. D: The mRNA expression levels of caspase-8 and bcl-2. E: The protein levels of caspase-8 and bcl-2. $* \mathrm{P}<0.05$.

Furthermore, qRT-PCR and western blotting showed that luteolin and chloroquine cotreatment decreased caspase 8 and increased bcl-2 mRNA and protein levels (Fig. 4D and $4 \mathrm{E})$. However, the apoptosis level after luteolin and chloroquine co-treatment was still higher than that in the $0 \mu \mathrm{M}$ luteolin-treated group.

\section{Discussion}

The antitumor activity of luteolin has been investigated in various cancer cells $[6,12,20$, 21]. For example, luteolin has been shown to induce cell cycle arrest and apoptosis, inhibit proliferation and metastatic progression, and attenuate doxorubicin-induced cytotoxicity [3, $7,20,22]$. Although luteolin could inhibit proliferation and induce cell apoptosis in the HCC 


\section{Cellular Physiology Cell Physiol Biochem 2017;43:1803-1812 \begin{tabular}{ll|l} 
and Biochemistry Published onlıne: October 19, 2017 & $\begin{array}{l}\text { (c) } 2017 \text { The Author(s). Published by S. Karger AG, Basel } \\
\text { www.karger.com/cpb }\end{array}$ \\
\hline
\end{tabular} \\ Cao et al.: Luteolin is a Regulator of Autophagy in HCC}

cell line HepG2 $[11,12]$, its role in regulating autophagy, and the relationship between cell apoptosis and autophagy, has not been elucidated in HCC. Therefore, we focused on these issues in present study.

In present study, we found that the inhibition by luteolin of cell viability and the induction of cell apoptosis was time-dependent and dose-dependent in the HCC cell line SMMC-7721. These results were consistent with previous studies in HepG2 cells. Although these results are a repeat of the results obtained in HepG2 cells, our results further indicated that luteolin has antitumor activity in HCC. In addition, we found that luteolin treatment induced a significant G0/G1-phase arrest, which might be the mechanism by which luteolin reduces cell viability.

There are two main apoptotic pathways: the extrinsic death receptor pathway and the intrinsic mitochondrial pathway $[13,23,24]$. The extrinsic pathway is initiated by DISC formation, Fas-associated death domain (FADD) or TRAIL-associated death domain binding to the death receptor, and pro-caspase- 8 activation. The intrinsic pathway is associated with mitochondrial-mediated signals via a decrease in the mitochondrial membrane potential and the release of pro-apoptotic proteins $[13,18,23,24]$. Bcl-2 family proteins, which include both anti-apoptotic proteins (such as bcl-2, bcl-xl, and bcl-w) and pro-apoptotic proteins (such as bax, bak, and bad), regulate the mitochondrial membrane potential and apoptosis sensitivity $[13,25]$. In the present study, we found that luteolin activated caspase-8, which regulates the extrinsic pathway. In addition, luteolin also reduced the expression of antiapoptotic protein bcl-2, which regulates the intrinsic mitochondrial pathway. Thus, we hypothesized that luteolin could regulate both the extrinsic and intrinsic pathways.

Autophagy is a lysosomal degradation pathway whereby damaged proteins and organelles are degraded to maintain cellular homeostasis [13, 26, 27]. Autophagy not only functions as a cell survival mechanism, but also can induce autophagic cell death when cells experience stress $[15,16,28,29]$. When autophagy is induced, beclin1 and LC3 are distributed to the autophagosome membrane to regulate autophagosome formation [13, 23]. In the present study, we found that luteolin treatment not only increased the number of intracellular autophagosomes, but also increased LC3B-I conversion to LC3B-II and Beclin 1 expression. These results demonstrated that luteolin could induce autophagy in the HCC cell line SMMC-7721. This conclusion is supported by observations in other physiological process. In human osteosarcoma U2OS cells, luteolin enhanced doxorubicin-induced autophagy [30]. In addition, luteolin treatment could stimulate autophagy in a Parkinson's disease model, in post-infarction cardiac dysfunction, and in foam cell formation [31-33].

Taken together, the results of this study confirmed that luteolin treatment could stimulate both apoptosis and autophagy in HCC cells. Therefore, we predicted that luteolin might promote cell apoptosis by inducing autophagy in HCC cells. Autophagy is a double-edged sword in cancer. In contrast to the tumor-suppressor roles of autophagy, stress-activated autophagy might promote tumor cell survival [13]. Autophagy and apoptosis both function as anticancer pathways; however, the crosstalk between autophagy and apoptosis in cancer is complex [13]. In present study, we found that co-treatment with the autophagy inhibitor chloroquine weakened the effect of luteolin on cellular apoptosis. These results indicated that autophagy could activate apoptosis in luteolin treated HCC cells. On the one hand, our result conflicted with certain previous studies that indicated that autophagy could suppress apoptosis in certain physiological process of cancer [34,35]. On the other hand, our results were supported by other studies that indicated that autophagy could promote apoptosis in certain physiological process of cancer [36, 37].

In conclusion, our results indicated that luteolin could suppress cell viability, induce G0/G1-phase arrest, and increase cellular apoptosis. These results indicated that luteolin has an antitumor effect in the HCC cell line SMMC-7721. Furthermore, luteolin could activate cellular apoptosis and co-treatment with the autophagy inhibitor chloroquine reduced the effect of luteolin on cell apoptosis, indicating that luteolin promotes cell apoptosis by inducing autophagy in HCC cells. Our study was the first to investigate the effect of luteolin 


\section{Cellular Physiology Cell Physiol Biochem 2017;43:1803-1812

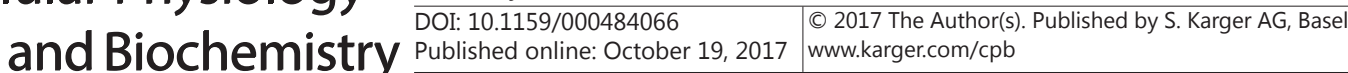 \\ Cao et al.: Luteolin is a Regulator of Autophagy in HCC}

on cell autophagy and the relationship between apoptosis and autophagy in luteolin-treated HCC cells. Our results will promote further research into the use of luteolin in HCC treatment.

\section{Acknowledgements}

This work was supported by the Science and Technology Research Project of Guangdong Province (No.2013B031800018) and the National Natural Science Foundation of China (No. 81102753) from P. R. China.

\section{Disclosure Statement}

The authors declare no Disclosure Statement.

\section{References}

1 Chen W, Zheng R, Zeng H, Zhang S, He J: Annual report on status of cancer in China, 2011. Chin J Cancer Res 2015;27:2-12.

-2 Balogh J, Victor D, 3rd, Asham EH, Burroughs SG, Boktour M, Saharia A, Li X, Ghobrial RM, Monsour HP, Jr:: Hepatocellular carcinoma: a review. J Hepatocell Carcinoma 2016;3:41-53.

-3 Sato Y, Sasaki N, Saito M, Endo N, Kugawa F, Ueno A: Luteolin attenuates doxorubicin-induced cytotoxicity to MCF-7 human breast cancer cells. Biol Pharm Bull 2015;38:703-709.

-4 Kandaswami C, Lee LT, Lee PP, Hwang JJ, Ke FC, Huang YT, Lee MT: The antitumor activities of flavonoids. In vivo 2005;19:895-909.

-5 Huang X, Dai S, Dai J, Xiao Y, Bai Y, Chen B, Zhou M: Luteolin decreases invasiveness, deactivates STAT3 signaling, and reverses interleukin-6 induced epithelial-mesenchymal transition and matrix metalloproteinase secretion of pancreatic cancer cells. Onco Targets Ther 2015;8:2989-3001.

6 Han K, Meng W, Zhang JJ, Zhou Y, Wang YL, Su Y, Lin SC, Gan ZH, Sun YN, Min DL: Luteolin inhibited proliferation and induced apoptosis of prostate cancer cells through miR-301. Onco Targets Ther 2016;9:3085-3094.

7 Naso LG, Badiola I, Marquez Clavijo J, Valcarcel M, Salado C, Ferrer EG, Williams PA: Inhibition of the metastatic progression of breast and colorectal cancer in vitro and in vivo in murine model by the oxidovanadium(IV) complex with luteolin. Bioorg Med Chem 2016;24:6004-6011.

8 Dia VP, Pangloli P: Epithelial-to-Mesenchymal Transition in Paclitaxel-Resistant Ovarian Cancer Cells Is Downregulated by Luteolin. J Cell Physiol 2017;232:391-401.

-9 Di D, Chen L, Wang L, Sun P, Liu Y, Xu Z, Ju J: Downregulation of human intercellular adhesion molecule-1 attenuates the metastatic ability in human breast cancer cell lines. Oncol Rep 2016;35:1541-1548.

$>10$ Niu JX, Guo HP, Gan HM, Bao LD, Ren JJ: Effect of luteolin on gene expression in mouse H22 hepatoma cells. Genet Mol Res 2015;14:14448-14456.

11 Xu H, Yang T, Liu X, Tian Y, Chen X, Yuan R, Su S, Lin X, Du G: Luteolin synergizes the antitumor effects of 5-fluorouracil against human hepatocellular carcinoma cells through apoptosis induction and metabolism. Life Sci 2016;144:138-147.

12 Yee SB, Choi HJ, Chung SW, Park DH, Sung B, Chung HY, Kim ND: Growth inhibition of luteolin on HepG2 cells is induced via p53 and Fas/Fas-ligand besides the TGF-beta pathway. Int J Oncol 2015;47:747-754.

13 El-Khattouti A, Selimovic D, Haikel Y, Hassan M: Crosstalk between apoptosis and autophagy: molecular mechanisms and therapeutic strategies in cancer. J Cell Death 2013;6:37-55.

14 Liang C: Negative regulation of autophagy. Cell Death Differ 2010;17:1807-1815.

15 Szczesny B, Brunyanszki A, Ahmad A, Olah G, Porter C, Toliver-Kinsky T, Sidossis L, Herndon DN, Szabo C: Time-Dependent and Organ-Specific Changes in Mitochondrial Function, Mitochondrial DNA Integrity, Oxidative Stress and Mononuclear Cell Infiltration in a Mouse Model of Burn Injury. PLoS One 2015;10:e0143730. 


\section{Cellular Physiology Cell Physiol Biochem 2017;43:1803-1812 \\ \begin{tabular}{l|l|l} 
DOI: 10.1159/000484066 & $\begin{array}{l}\text { O 2017 The Author(s). Published by S. Karger AG, Basel } \\
\text { www.karger.com/cpb }\end{array}$ \\
\hline
\end{tabular}}

Cao et al.: Luteolin is a Regulator of Autophagy in HCC

16 Li X, Xu HL, Liu YX, An N, Zhao S, Bao JK: Autophagy modulation as a target for anticancer drug discovery. Acta Pharmacol Sin 2013;34:612-624.

17 Maiuri MC, Zalckvar E, Kimchi A, Kroemer G: Self-eating and self-killing: crosstalk between autophagy and apoptosis. Nat Rev Mol Cell Biol 2007;8:741-752.

-18 Lockshin RA, Zakeri Z: Apoptosis, autophagy, and more. Int J Biochem Cell Biol 2004;36:2405-2419.

19 Livak KJ, Schmittgen TD: Analysis of relative gene expression data using real-time quantitative PCR and the 2(-Delta Delta C(T)) Method. Methods 2001;25:402-408.

-20 Park SH, Ham S, Kwon TH, Kim MS, Lee DH, Kang JW, Oh SR, Yoon DY: Luteolin induces cell cycle arrest and apoptosis through extrinsic and intrinsic signaling pathways in MCF-7 breast cancer cells. J Environ Pathol Toxicol Oncol 2014;33:219-231.

21 Sun DW, Zhang HD, Mao L, Mao CF, Chen W, Cui M, Ma R, Cao HX, Jing CW, Wang Z, Wu JZ, Tang JH: Luteolin Inhibits Breast Cancer Development and Progression In vitro and In vivo by Suppressing Notch Signaling and Regulating MiRNAs. Cell Physiol Biochem 2015;37:1693-1711.

22 Sui JQ Xie KP, Xie MJ: Inhibitory effect of luteolin on the proliferation of human breast cancer cell lines induced by epidermal growth factor. Sheng Li Xue Bao 2016;68:27-34.

-23 Thorburn A: Apoptosis and autophagy: regulatory connections between two supposedly different processes. Apoptosis 2008;13:1-9.

24 Nikoletopoulou V, Markaki M, Palikaras K, Tavernarakis N: Crosstalk between apoptosis, necrosis and autophagy. Biochim Biophys Acta 2013;1833:3448-3459.

-25 Hassan M, Alaoui A, Feyen O, Mirmohammadsadegh A, Essmann F, Tannapfel A, Gulbins E, Schulze-Osthoff $\mathrm{K}$, Hengge UR: The BH3-only member Noxa causes apoptosis in melanoma cells by multiple pathways. Oncogene 2008;27:4557-4568.

26 Mizushima N, Komatsu M: Autophagy: renovation of cells and tissues. Cell 2011;147:728-741.

-27 Quan W, Jung HS, Lee MS: Role of autophagy in the progression from obesity to diabetes and in the control of energy balance. Arch Pharm Res 2013;36:223-229.

-28 Lamy L, Ngo VN, Emre NC, Shaffer AL, 3rd, Yang Y, Tian E, Nair V, Kruhlak MJ, Zingone A, Landgren O, Staudt LM: Control of autophagic cell death by caspase-10 in multiple myeloma. Cancer Cell 2013;23:435-449.

-29 Luo YH, Wu SB, Wei YH, Chen YC, Tsai MH, Ho CC, Lin SY, Yang CS, Lin P: Cadmium-based quantum dot induced autophagy formation for cell survival via oxidative stress. Chem Res Toxicol 2013;26:662-673.

-30 Zhang B, Yu X, Xia H: The flavonoid luteolin enhances doxorubicin-induced autophagy in human osteosarcoma U2OS cells. Int J Clin Exp Med 2015;8:15190-15197.

-31 Siracusa R, Paterniti I, Impellizzeri D, Cordaro M, Crupi R, Navarra M, Cuzzocrea S, Esposito E: The Association of Palmitoylethanolamide with Luteolin Decreases Neuroinflammation and Stimulates Autophagy in Parkinson's Disease Model. CNS Neurol Disord Drug Targets 2015;14:1350-1365.

-32 Hu J, Man W, Shen M, Zhang M, Lin J, Wang T, Duan Y, Li C, Zhang R, Gao E, Wang H, Sun D: Luteolin alleviates post-infarction cardiac dysfunction by up-regulating autophagy through Mst1 inhibition. J Cell Mol Med 2016;20:147-156.

-33 Zhang BC, Zhang CW, Wang C, Pan DF, Xu TD, Li DY: Luteolin Attenuates Foam Cell Formation and Apoptosis in Ox-LDL-Stimulated Macrophages by Enhancing Autophagy. Cell Physiol Biochem 2016;39:2065-2076.

-34 Chen L, Li G, Peng F, Jie X, Dongye G, Cai K, Feng R, Li B, Zeng Q, Lun K, Chen J, Xu B: The induction of autophagy against mitochondria-mediated apoptosis in lung cancer cells by a ruthenium (II) imidazole complex. Oncotarget 2016; 7:80716-80734.

-35 Pan X, Zhang X, Sun H, Zhang J, Yan M, Zhang H: Autophagy inhibition promotes 5-fluorouraci-induced apoptosis by stimulating ROS formation in human non-small cell lung cancer A549 cells. PLoS One 2013;8:e56679.

-36 Chen L, Meng Y, Guo X, Sheng X, Tai G, Zhang F, Cheng H, Zhou Y: Gefitinib enhances human colon cancer cells to TRAIL-induced apoptosis of via autophagy- and JNK-mediated death receptors upregulation. Apoptosis 2016;21:1291-1301.

-37 So KY, Oh SH: Heme oxygenase-1-mediated apoptosis under cadmium-induced oxidative stress is regulated by autophagy, which is sensitized by tumor suppressor p53. Biochem Biophys Res Commun 2016;479:8085. 